\title{
Trends in postpartum hemorrhage from 2000 to 2009: a population-based study
}

\author{
Azar Mehrabadi ${ }^{1,2^{*}}$, Jennifer A Hutcheon ${ }^{1,2,3}$, Lily Lee ${ }^{3}$, Robert M Liston ${ }^{1}$ and KS Joseph ${ }^{1,2,3}$
}

\begin{abstract}
Background: Postpartum hemorrhage, a major cause of maternal death and severe maternal morbidity, increased in frequency in Canada between 1991 and 2004. We carried out a study to describe the epidemiology of postpartum hemorrhage in British Columbia, Canada, between 2000 and 2009.

Methods: The study population included all women residents of British Columbia who delivered between 2000 and 2009. Data on postpartum hemorrhage by subtypes and severity were obtained from the British Columbia Perinatal Data Registry. Among women with postpartum hemorrhage, severe cases were identified by the use of blood transfusions or procedures to control bleeding. Rates of postpartum hemorrhage and changes over time were assessed using rates, rate ratios and 95\% confidence intervals $(\mathrm{Cl})$.

Results: The rate of postpartum hemorrhage increased by 27\% (95\% Cl 21-34\%) between 2000 and 2009 (from $6.3 \%$ to $8.0 \%$ ), while atonic postpartum hemorrhage rates increased by $33 \%(95 \% \mathrm{Cl} 26-41 \%)$ from $4.8 \%$ to $6.4 \%$. Atonic postpartum hemorrhage with blood transfusion increased from 17.8 to 25.5 per 10,000 deliveries from 2000 to 2009 and atonic postpartum hemorrhage with either suturing of the uterus, ligation of pelvic vessels or embolization increased from 1.8 to 5.6 per 10,000 deliveries from 2001 to 2009. The increase in atonic postpartum hemorrhage was most evident between 2006 and 2009 and occurred across regions, hospitals and various maternal, fetal and obstetric characteristics.
\end{abstract}

Conclusions: Atonic postpartum hemorrhage and severe atonic postpartum hemorrhage increased in British Columbia between 2000 and 2009. Further research is required to identify the cause of the increase.

\section{Background}

Postpartum hemorrhage is a major cause of maternal death worldwide and an important cause of severe maternal morbidity in high income countries [1]. In its severe form, postpartum hemorrhage represents a lifethreatening obstetrical emergency [2]. Postpartum hemorrhage rates have increased in Canada and elsewhere from 1991 to 2004 [3]. Initial reports from Canada identified the problem as a rise in rates of severe postpartum hemorrhage, specifically an increase in rates of postpartum hemorrhage requiring hysterectomy between 1991 and 1999 [4]. This was followed by reports

\footnotetext{
* Correspondence: azar@interchange.ubc.ca

'Department of Obstetrics and Gynaecology, University of British Columbia and the Children's and Women's Health Centre of British Columbia, Room E418B, Shaughnessy Bldg, 4500 Oak Street, Vancouver, BC V6H 3N1, Canada ${ }^{2}$ School of Population and Public Health, University of British Columbia, Vancouver, BC, Canada

Full list of author information is available at the end of the article
}

which showed that the epidemic was restricted to one type of postpartum hemorrhage, namely, atonic postpartum hemorrhage [5]. Increases in postpartum hemorrhage and severe postpartum hemorrhage have also been reported in Australia, Ireland, Scotland, Norway and the United States during the same time period [6-9]. The increase in postpartum hemorrhage has occurred against a background of increases in older maternal age, obesity, multiple births, deliveries to women with a previous cesarean, induction and augmentation of labour, and cesarean deliveries [5,6,8]. However, the causes for the increase in atonic postpartum hemorrhage remain unclear $[5,10,11]$. We carried out a study to characterize continuing trends in postpartum hemorrhage beyond 2004, with the goal of identifying potential causative factors and the clinical and population health implications. Our objective was to estimate the incidence of overall postpartum hemorrhage and its subtypes in British Columbia, Canada, between 2000

\section{Biomed Central}


and 2009 and to describe the epidemiologic features of postpartum hemorrhage.

\section{Methods}

The study population included all women, residents of British Columbia, who delivered between 2000 and 2009. Data were obtained from the British Columbia Perinatal Data Registry, a population-based registry whose purpose is to collect and disseminate perinatal data for research, surveillance and planning. The database contains information on approximately $99 \%$ of births in the province, including detailed clinical and diagnostic information. Standardized forms were filledout by care providers (physicians, midwives, obstetricians, and nurses) during pregnancy, labour and delivery and postpartum, and then compiled and coded by trained data abstractors. Accuracy and validity of data is ensured through ongoing quality checks by staff, automated data rules and ongoing use in research and surveillance. All women who gave birth between April $1^{\text {st }}$, 2000 and March $31^{\text {st }}, 2010$ (hereafter referred to as years 2000 to 2009) and who resided in British Columbia were included in the study. This study received ethical approval from the University of British Columbia Children's \& Women's Health Centre Research Ethics Board.

Postpartum hemorrhage in Canada is defined as an estimated blood loss of $\geq 500 \mathrm{~mL}$ after vaginal delivery or $\geq 1000 \mathrm{~mL}$ after cesarean delivery or as otherwise diagnosed by a care provider. Postpartum hemorrhage diagnoses were based on International Classification of Diseases (ICD) codes recorded in the Perinatal Database (ICD-9 from 2000 to 2003 and ICD-10 from 2004 to 2009). Subtypes of postpartum hemorrhage identified with ICD-9 or ICD-10 diagnostic codes included: 1) postpartum hemorrhage due to retained placenta (third stage hemorrhage), 2) postpartum hemorrhage due to uterine atony (occurring within 24 hours following delivery), 3) delayed and secondary postpartum hemorrhage (occurring after the first 24 hours following delivery) and 4) postpartum hemorrhage due to coagulation defects. Code details for postpartum hemorrhage did not change between ICD-9 and ICD-10.

Severe cases were defined as postpartum hemorrhage diagnosis in conjunction with blood transfusion, hysterectomy, or other procedures to control bleeding. Blood transfusion was defined as receipt of one or more units of whole or packed red blood cells. Hysterectomy and procedures to control bleeding were based on the Canadian Classification of Health Interventions (CCI), which was used from April 1 $1^{\text {st }}, 2001$ onwards. Interventions and procedures to control bleeding in conjunction with a diagnosis of postpartum hemorrhage included hysterectomy, bimanual uterine compression and massage, uterine (and vaginal) packing, ligation of pelvic vessels, and embolization of pelvic vessels (see Additional file 1: Table S1 for all diagnostic codes and procedures). Between 2001 and 2003, 2,156 of 118,987 women (1.8\%) were missing CCI procedure codes for hysterectomy or procedures to control bleeding and so equivalent Canadian Classification of Diagnostic, Therapeutic and Surgical Procedures (CCP) codes for hysterectomy were used (Additional file 1: Table S1). For other procedures to control bleeding, CCP codes could not be used as these procedure codes were introduced in the CCI. However exclusion of records made very little difference to either rates or statistical test results, so patients were included in the reported results.

Maternal, fetal and obstetrical characteristics were identified according to fields recorded in the Perinatal Data Registry. Maternal characteristics included parity, age, and body mass index (BMI) and fetal characteristics included plurality, birth weight and gestational age. Obstetrical factors included spontaneous or instrumental vaginal delivery (with vacuum or forceps), cesarean delivery with or without labour, previous cesarean delivery, any method of labour induction, augmentation with oxytocin, and administration of epidural analgesia. Geographic regions of British Columbia were defined by the regional health authority of the mother's residence, and hospital volume was defined by number of deliveries per year, in the year of delivery. Length of hospital stay greater than 4 days and hospital stay greater than 7 days were used as a measure of the burden of illness associated with postpartum hemorrhage. The 4 day cut-off was chosen as it is greater than the average stay for both cesarean and vaginal deliveries, while the 7 days postpartum cut-off has previously been used as an indicator for severe maternal morbidity $[12,13]$.

Rates and exact binomial 95\% confidence intervals were estimated for overall postpartum hemorrhage (and its subtypes), severe postpartum hemorrhage, and severe atonic postpartum hemorrhage for the period 2000 to 2009 and for each year within this time period. Temporal trends were assessed both by contrasting the rates in 2000 or 2001 with rates in 2009 using rate ratios (RR) and 95\% confidence limits (95\% CI). Temporal trends were also examined across all the years in the study using a chi-square test for linear trends in proportions. Statistical significance of differences was assessed based on two-sided $\mathrm{p}$ values and a $\mathrm{p}$ value $<0.05$ was considered statistically significant. STATA version 11.2 was used to model smoothed rates and 95\% confidence intervals overlaid on observed semiannual rates [14]. Calendar time was modelled using a restricted cubic spline, thereby avoiding linearity assumptions and loss of information from categorizing the continuous time variable [15]. For all other 
analysis, we used SAS version 9.2 statistical software and Epi Info (wwwn.cdc.gov/epiinfo/).

\section{Results}

Between 2000 and 2009, 412,093 women residents of British Columbia delivered either a live birth or stillbirth and were included in the study. Postpartum hemorrhage rates increased from $6.3 \%$ in 2000 to $8.0 \%$ in 2009 , a $27 \%$ increase (95\% CI 21-34\%), while atonic postpartum hemorrhage increased from $4.8 \%$ in 2000 to $6.4 \%$ in 2009 , a $33 \%$ increase $(95 \%$ CI $26-41 \%$, Table 1$)$. The increase in postpartum hemorrhage and atonic postpartum hemorrhage was particularly evident between 2006 and 2009 (Figure 1A). Overall postpartum hemorrhage and atonic postpartum hemorrhage showed an increasing linear trend between 2000 and $2009(p<0.001)$. Other subtypes of postpartum hemorrhage did not show similar increasing trends (Figure 1A); there was a 40\% (95\% CI 9-81\%) increase in secondary postpartum hemorrhage from $0.25 \%$ in 2000 to $0.35 \%$ in 2009 , but the temporal trend using information for all years was not significant $(\mathrm{p}=0.27$, Table 1$)$.

Severe postpartum hemorrhage increased significantly according to every indicator analyzed except for postpartum hemorrhage with hysterectomy. Postpartum hemorrhage with blood transfusion increased from 29.1 to 42.5 per 10,000 deliveries from 2000 to 2009 (an increase of $46 \%, 95 \%$ CI 16-84\%), while postpartum hemorrhage with uterine (and vaginal) packing increased by $102 \%$ (95\% CI 12-263\%) from 2001 to 2009. Postpartum hemorrhage with either suturing of the uterus, ligation of pelvic vessels or embolization increased by 297\% (95\% CI 75-801\%, Table 1). Severe atonic postpartum hemorrhage demonstrated a trend similar to trends in severe overall postpartum hemorrhage; all procedures indicating severe atonic postpartum hemorrhage increased significantly over time (Table 1). Atonic postpartum hemorrhage with blood transfusion increased

Table 1 Temporal trends in postpartum hemorrhage (PPH), PPH subtypes, severe PPH and severe atonic PPH in British Columbia, 2000-2009

\begin{tabular}{|c|c|c|c|c|c|c|c|c|}
\hline & \multirow{2}{*}{$\frac{\text { All years }}{n^{1}}$} & \multicolumn{4}{|c|}{ PPH rate } & \multicolumn{2}{|c|}{2009 vs. $2000 / 2001$} & \multirow{2}{*}{$\begin{array}{l}P \text { for } \\
\text { trend }\end{array}$} \\
\hline & & 2000 & 2001 & 2008 & 2009 & RR & $95 \% \mathrm{Cl}$ & \\
\hline \multicolumn{9}{|l|}{ PPH (rates per 100 deliveries): } \\
\hline All PPH & 28221 & 6.3 & 6.3 & 8.2 & 8.0 & 1.27 & $1.21-1.34$ & $<0.001$ \\
\hline Due to retained placenta & 4859 & 1.3 & 1.2 & 1.3 & 1.3 & 1.02 & $0.90-1.15$ & 0.81 \\
\hline Atonic & 22100 & 4.8 & 4.8 & 6.6 & 6.3 & 1.33 & $1.26-1.41$ & $<0.001$ \\
\hline Secondary & 1276 & 0.25 & 0.34 & 0.29 & 0.35 & 1.40 & $1.09-1.81$ & 0.27 \\
\hline Due to coagulation defects & 178 & 0.05 & 0.05 & 0.05 & 0.03 & 0.51 & $0.25-1.05$ & 0.14 \\
\hline \multicolumn{9}{|l|}{ Severe PPH (rates per 10,000 deliveries): } \\
\hline $\mathrm{PPH}+$ blood transfusion & 1468 & 29.1 & 30.3 & 45.1 & 42.5 & 1.46 & $1.16-1.84$ & $<0.001$ \\
\hline $\mathrm{PPH}+$ hysterectomy & 215 & - & 4.8 & 7.1 & 4.7 & 0.99 & $0.53-1.84$ & 0.76 \\
\hline $\mathrm{PPH}+$ suturing of uterus & 65 & - & 0 & 3.4 & 3.2 & - & - & $<0.001$ \\
\hline $\mathrm{PPH}+$ bimanual compression and massage & 2255 & - & 27.7 & 98.1 & 95.6 & 3.45 & $2.79-4.25$ & $<0.001$ \\
\hline $\mathrm{PPH}+$ uterine (and vaginal) packing & 223 & - & 4.0 & 6.4 & 8.1 & 2.02 & $1.12-3.63$ & 0.02 \\
\hline $\mathrm{PPH}+$ ligation of pelvic vessels & 81 & - & 1.3 & 3.9 & 4.5 & 3.58 & $1.34-9.55$ & $<0.001$ \\
\hline $\mathrm{PPH}+$ embolization of pelvic vessels & 60 & - & 0.50 & 2.5 & 1.4 & 2.69 & $0.54-13.32$ & 0.01 \\
\hline PPH + Suture, ligation, or embolization & 186 & - & 1.8 & 9.1 & 7.0 & 3.97 & $1.75-9.01$ & $<0.001$ \\
\hline \multicolumn{9}{|l|}{ Severe atonic PPH (rates per 10,000 deliveries) } \\
\hline Atonic PPH + blood transfusion & 876 & 17.8 & 16.6 & 28.2 & 25.5 & 1.43 & $1.07-1.93$ & $<0.001$ \\
\hline Atonic PPH + hysterectomy & 108 & - & 2.5 & 3.6 & 1.8 & 0.72 & $0.28-1.81$ & 0.37 \\
\hline Atonic PPH + suturing of uterus & 55 & - & 0 & 2.7 & 2.9 & - & - & $<0.001$ \\
\hline Atonic PPH + bimanual compression and massage & 1964 & - & 23.5 & 85.3 & 81.8 & 3.49 & $2.78-4.38$ & $<0.001$ \\
\hline Atonic PPH + uterine (and vaginal) packing & 174 & - & 3.0 & 5.9 & 5.9 & 1.93 & $0.97-3.82$ & 0.02 \\
\hline Atonic PPH + ligation of pelvic vessels & 68 & - & 1.3 & 3.9 & 3.6 & 2.87 & $1.05-7.83$ & $<0.001$ \\
\hline Atonic PPH + embolization of pelvic vessels & 43 & - & 0.50 & 2.0 & 1.1 & 2.24 & $0.43-11.55$ & 0.01 \\
\hline Atonic PPH + Suture, ligation, or embolization & 150 & - & 1.8 & 8.0 & 5.6 & 3.20 & $1.38-7.40$ & $<0.001$ \\
\hline
\end{tabular}

${ }^{1} n$ refers to number of cases of the outcome of interest.

${ }^{2} \mathrm{P}$ value based on data for all years between 2000 (or 2001) and 2009.

RR denotes rate ratio and $95 \% \mathrm{Cl}$ denotes $95 \%$ confidence intervals. 


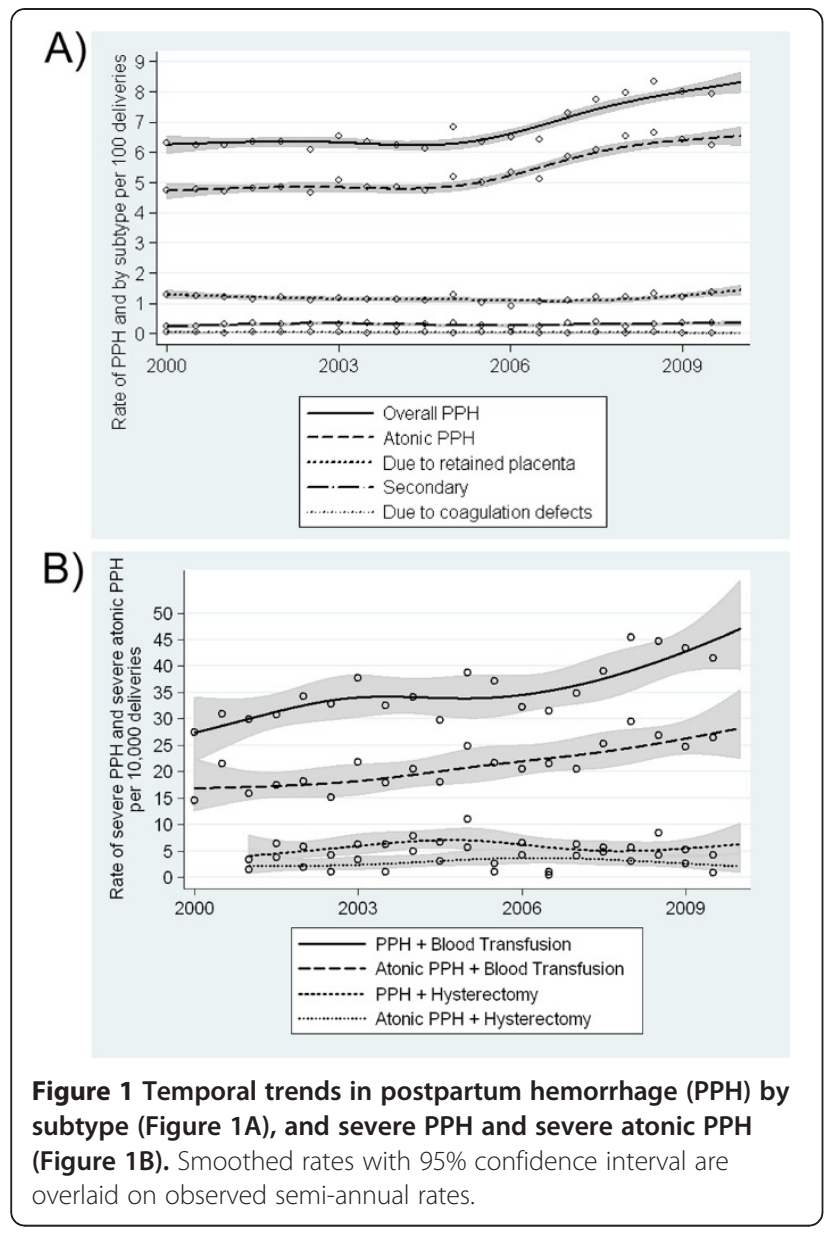

from 17.8 per 10,000 deliveries in 2000 to 25.5 per 10,000 deliveries in 2009 (43\% increase, 95\% CI 7-93\%), while atonic postpartum hemorrhage with either suturing of the uterus, ligation of pelvic vessels or embolization increased from 1.8 in 2001 to 5.6 per 10,000 deliveries in 2009 (220\% increase, 95\% CI 38-640\%). Most of the observed increase in overall postpartum hemorrhage with blood transfusion occurred between 2006 and 2009, while atonic postpartum hemorrhage with blood transfusion rates increased at a constant rate between 2003 and 2009 (Figure 1B).

Atonic postpartum hemorrhage increased significantly between 2000 and 2009 across all regions (except for the Northern Health Authority which showed a decrease) and increased significantly across hospitals irrespective of hospital volume (except for those with 1000-1499 deliveries per year, Table 2). Atonic postpartum hemorrhage rates were higher among the large volume hospitals as compared with the small volume hospitals $(6.1 \%$ compared with $4.5 \%)$. Supplementary analysis showed that women residing in the Northern Health Authority were younger, more likely to be multiparous, and less likely to receive epidural analgesia or undergo an instrumental vaginal delivery. Rates of epidural analgesia also decreased slightly $(\mathrm{p}<0.05)$ in this region, while rates increased significantly in all other regions.

Atonic postpartum hemorrhage increased significantly between 2000 and 2009 across all maternal, fetal and obstetric characteristics under study with the exception of birthweight $<2500$ grams, and gestational ages $<28$ weeks or $\geq 42$ weeks (Table 3 ). An increase in atonic postpartum hemorrhage was observed both among women with vaginal deliveries and cesarean deliveries, and regardless of whether a women had a previous cesarean delivery. Among cesarean deliveries, atonic postpartum hemorrhage increased significantly among all cesarean sub-categories, including cesareans without labour, those with spontaneous labour and those who had labour induction. Among women with a vaginal delivery, atonic postpartum hemorrhage increased more markedly among those with an instrumental vaginal delivery. Atonic postpartum hemorrhage increased significantly regardless of whether a woman had her labour induced, was augmented with oxytocin, or received epidural analgesia. The percent increase, however, was higher among women receiving these procedures.

Trends in atonic postpartum hemorrhage with blood transfusion were more variable over time across maternal, fetal and obstetric characteristics, likely due to smaller numbers for this outcome (Table 4). Significant and non-significant increases were observed across many maternal, fetal and obstetric categories. Notably, increases in atonic postpartum hemorrhage with blood transfusion were evident among both spontaneous and instrumental vaginal deliveries, although the increase was greater for instrumental vaginal births. Additionally, increases were evident among women irrespective of use of labour induction, oxytocin augmentation, or epidural analgesia. Increases in atonic postpartum hemorrhage with blood transfusion among women with a cesarean delivery were only observed among cesareans following labour induction. Although atonic postpartum hemorrhage rates were higher for vaginal as compared with cesarean deliveries (Table 3), rates of atonic postpartum hemorrhage with blood transfusion (as well as all other types of severe atonic postpartum hemorrhage - data not shown) were higher among cesarean as compared with vaginal deliveries (Table 4).

Women with postpartum hemorrhage were more likely to have long hospital stays; $9.5 \%$ of women with postpartum hemorrhage had a length of stay greater than 4 days compared with $7.2 \%$ of women without postpartum hemorrhage ( $R R=1.32$, 95\% CI 1.27-1.37), and 1.3\% had a length of stay greater than 7 days as compared with $0.7 \%$ 
Table 2 Atonic postpartum hemorrhage by region and hospital volume, British Columbia, 2000-2009

\begin{tabular}{|c|c|c|c|c|c|c|c|c|c|}
\hline \multirow{2}{*}{$\begin{array}{l}\text { Region (by health authority of mother's } \\
\text { residence) }\end{array}$} & \multicolumn{2}{|c|}{ All years } & \multicolumn{4}{|c|}{ Rate per 100 deliveries by year } & \multicolumn{2}{|c|}{2009 vs. 2000} & \multirow{2}{*}{$\begin{array}{l}\mathrm{P} \text { for } \\
\text { trend }\end{array}$} \\
\hline & $\overline{n^{1}}$ & $\overline{\text { rate }}$ & 2000 & 2001 & 2008 & 2009 & $\overline{\mathrm{RR}}$ & $95 \% \mathrm{Cl}$ & \\
\hline Fraser & 8340 & 5.2 & 5.0 & 4.9 & 6.6 & 6.0 & 1.19 & $1.09-1.30$ & $<0.001$ \\
\hline Interior & 2769 & 4.7 & 3.9 & 3.4 & 5.8 & 7.0 & 1.81 & $1.54-2.11$ & $<0.001$ \\
\hline Northern & 1694 & 4.9 & 5.2 & 4.8 & 5.6 & 4.1 & 0.79 & $0.64-0.97$ & 0.03 \\
\hline Vancouver Coastal & 6995 & 7.1 & 5.4 & 6.0 & 8.8 & 8.3 & 1.55 & $1.39-1.72$ & $<0.001$ \\
\hline Vancouver Island & 2206 & 3.7 & 3.8 & 3.8 & 4.4 & 4.9 & 1.29 & $1.09-1.53$ & $<0.001$ \\
\hline
\end{tabular}

Hospital Volume (by deliveries per year)

\begin{tabular}{|c|c|c|c|c|c|c|c|c|c|}
\hline$<500$ & 2537 & 4.5 & 5.0 & 4.1 & 5.6 & 5.2 & 1.04 & $0.88-1.2$ & $<0.001$ \\
\hline 500-999 & 2363 & 4.6 & 3.8 & 4.0 & 5.6 & 5.6 & 1.49 & $1.27-1.75$ & $<0.001$ \\
\hline 1000-1499 & 3369 & 4.2 & 5.6 & 4.4 & 5.3 & 4.0 & 0.71 & $0.61-0.84$ & 0.88 \\
\hline $1500-2499$ & 3851 & 6.3 & 1.5 & 4.9 & 8.4 & 8.2 & 5.45 & $4.30-6.92$ & $<0.001$ \\
\hline$\geq 2500$ & 9980 & 6.1 & 5.6 & 5.5 & 6.8 & 6.5 & 1.15 & $1.05-1.25$ & $<0.001$ \\
\hline
\end{tabular}

${ }^{1} \mathrm{n}$ refers to number of cases of atonic postpartum hemorrhage.

${ }^{2} \mathrm{P}$ value based on data for all years between 2000 and 2009.

RR denotes rate ratio and $95 \% \mathrm{Cl}$ denotes $95 \%$ confidence intervals.

of women without postpartum hemorrhage $(\mathrm{RR}=1.88$, 95\% CI 1.69-2.10).

\section{Discussion}

Previous studies have reported an increase in postpartum hemorrhage between 1991 and 2004 and in severe postpartum hemorrhage between 2003 and 2007 in Canada $[5,16]$. Our population-based study from British Columbia demonstrated that postpartum hemorrhage rates continued to increase until 2009 with a steep increase between 2006 and 2009. The increase was driven by a $33 \%$ rise in atonic postpartum hemorrhage. There was a $43 \%$ increase in atonic postpartum hemorrhage with blood transfusion and a $220 \%$ increase in atonic postpartum hemorrhage with either uterine suturing, ligation of pelvic vessels or embolization.

The increase in overall and atonic postpartum hemorrhage since 2006 coincides with a change in the definition of postpartum hemorrhage in the Canadian Institute for Health Information 2006 coding standards [17]. Increases in postpartum hemorrhage diagnoses around this time period were also reported elsewhere in Canada. A recent database report from Nova Scotia documented a $24 \%$ increase in postpartum hemorrhage from 2004 to 2005 , from $5.0 \%$ to $6.2 \%$, followed by a $29 \%$ increase between 2006 and 2007, from $6.2 \%$ to $8.0 \%$ [18]. Although these increases may be partly explained by this definition change, the increase was also observed for severe postpartum hemorrhage and severe atonic postpartum hemorrhage (as measured by concurrent blood transfusion or procedures to control bleeding). The latter are considered objective and clinically important measures of severity. Additionally, the increase did not occur for all subtypes of postpartum hemorrhage as would be expected with a change in the definition of postpartum hemorrhage.

Postpartum hemorrhage rates increased across the majority of maternal, fetal and obstetric characteristics and this finding does not point to any single cause. Notably, atonic postpartum hemorrhage increased even among cesarean deliveries with no labour or labour induction. One mechanism suggested for uterine atony (and for the current postpartum hemorrhage epidemic [10]) is desensitization of uterine tissue to oxytocin due to its liberal administration during labour induction and augmentation [19]. However the observed increase in postpartum hemorrhage occurred even among women not induced or augmented, highlighting the fact that other causes may be responsible. Factors not associated with an increasing trend in postpartum hemorrhage (such as gestational age $<28$ weeks) typically had a low frequency and such findings are not inconsistent with an across-the-board increase in postpartum hemorrhage. The higher rates of atonic postpartum hemorrhage among vaginal deliveries (as opposed to cesarean deliveries) may be related to differing definitions of postpartum hemorrhage for these two routes of delivery. Cesarean deliveries were associated with higher rates of severe atonic postpartum hemorrhage than vaginal deliveries (Table 4).

The declining trend in postpartum hemorrhage among women from the Northern Health Authority may provide some etiologic insight into the increases seen elsewhere. The inter-relationship between risk factors for postpartum hemorrhage such epidural analgesia, oxytocin induction and instrumental vaginal delivery require further investigation in order to delineate their relative contributions to the change in postpartum hemorrhage rates. On the other hand, the Northern Health Authority 
Table 3 Temporal Trends in atonic postpartum hemorrhage by maternal, fetal and obstetrical characteristics, British Columbia, 2000-2009

\begin{tabular}{|c|c|c|c|c|c|c|c|c|c|}
\hline & \multicolumn{2}{|c|}{ All years } & \multicolumn{4}{|c|}{ Rate per 100 deliveries } & \multicolumn{2}{|c|}{2009 vs. 2000} & \multirow{2}{*}{$\begin{array}{l}\mathrm{P} \text { for } \\
\text { trend }\end{array}$} \\
\hline & $\overline{n^{1}}$ & $\overline{\text { rate }}$ & 2000 & 2001 & 2008 & 2009 & $\overline{\mathrm{RR}}$ & $95 \% \mathrm{Cl}$ & \\
\hline \multicolumn{10}{|l|}{ Parity } \\
\hline Nulliparous & 12,237 & 6.5 & 5.5 & 5.5 & 8.1 & 7.6 & 1.39 & $1.29-1.51$ & $<0.001$ \\
\hline Parous & 9,863 & 4.4 & 4.2 & 4.2 & 5.3 & 5.2 & 1.24 & $1.14-1.35$ & $<0.001$ \\
\hline \multicolumn{10}{|c|}{ Maternal age (years) } \\
\hline$<20$ & 953 & 6.2 & 6.1 & 5.0 & 8.5 & 7.6 & 1.26 & $0.97-1.62$ & $<0.001$ \\
\hline $20-34$ & 16,641 & 5.4 & 4.8 & 4.8 & 6.6 & 6.4 & 1.34 & $1.26-1.43$ & $<0.001$ \\
\hline$\geq 35$ & 4,506 & 5.2 & 4.4 & 4.7 & 6.3 & 5.9 & 1.34 & $1.18-1.53$ & $<0.00$ \\
\hline
\end{tabular}

BMI

\begin{tabular}{llllllllll}
\hline Underweight & 1,032 & 6.0 & 4.8 & 5.2 & 7.4 & 6.8 & 1.43 & $1.09-1.87$ & $<0.001$ \\
\hline Normal & 9,960 & 5.7 & 5.1 & 5.1 & 6.9 & 6.8 & 1.33 & $1.22-1.47$ & $<0.001$ \\
\hline Overweight & 2,977 & 5.1 & 4.5 & 4.5 & 6.2 & 6.2 & 1.39 & $1.19-1.62$ & $<0.001$ \\
\hline Obese & 1,583 & 4.9 & 4.2 & 4.4 & 6.4 & 5.5 & 1.31 & $1.06-1.63$ & $<0.001$ \\
\hline Plurality & & & & & & & & & \\
\hline Singleton & 21,529 & 5.3 & 4.7 & 4.7 & 6.5 & 6.3 & 1.33 & $1.25-1.41$ & $<0.001$ \\
\hline Multiple & 571 & 9.2 & 7.1 & 10.8 & 11.3 & 9.4 & 1.33 & $0.91-1.95$ & $<0.001$ \\
\hline
\end{tabular}

Birthweight (grams)

\begin{tabular}{|c|c|c|c|c|c|c|c|c|c|}
\hline$<2500$ & 794 & 3.7 & 3.2 & 4.0 & 5.0 & 3.7 & 1.17 & $0.85-1.61$ & 0.03 \\
\hline $2500-3999$ & 17,353 & 5.2 & 4.5 & 4.5 & 6.3 & 6.2 & 1.37 & $1.29-1.47$ & $<0.001$ \\
\hline$\geq 4000$ & 3,939 & 7.2 & 6.6 & 6.4 & 9.1 & 8.2 & 1.24 & $1.09-1.41$ & $<0.001$ \\
\hline \multicolumn{10}{|l|}{ Gestational age (weeks) } \\
\hline$<28$ & 68 & 2.0 & 2.14 & 0.69 & 3.13 & 1.5 & 0.71 & $0.25-2.01$ & 0.53 \\
\hline $28-36$ & 1,477 & 4.5 & 3.3 & 4.2 & 6.0 & 5.2 & 1.55 & $1.21-1.97$ & $<0.001$ \\
\hline $37-41$ & 20,115 & 5.5 & 4.9 & 4.8 & 6.7 & 6.5 & 1.33 & $1.25-1.41$ & $<0.001$ \\
\hline$\geq 42$ & 396 & 6.2 & 5.8 & 5.3 & 6.9 & 5.9 & 1.03 & $0.68-1.57$ & 0.52 \\
\hline \multicolumn{10}{|l|}{ Vaginal delivery } \\
\hline Spontaneous & 14,400 & 5.8 & 5.1 & 5.2 & 7.1 & 6.8 & 1.33 & $1.24-1.42$ & $<0.001$ \\
\hline Instrumental & 5,141 & 11.5 & 8.9 & 10.3 & 14.6 & 14.2 & 1.59 & $1.42-1.79$ & $<0.001$ \\
\hline \multicolumn{10}{|l|}{ Cesarean delivery } \\
\hline No labour & 912 & 1.7 & 1.6 & 1.3 & 2.1 & 2.1 & 1.28 & $0.94-1.73$ & $<0.001$ \\
\hline With labour, no induction & 1,001 & 2.4 & 1.6 & 1.5 & 3.5 & 3.0 & 1.92 & $1.43-2.58$ & $<0.001$ \\
\hline With induction & 646 & 2.9 & 1.9 & 1.5 & 3.9 & 3.5 & 1.74 & $1.20-2.54$ & $<0.001$ \\
\hline
\end{tabular}

\section{Previous cesarean}

\begin{tabular}{|c|c|c|c|c|c|c|c|c|c|}
\hline Yes & 1,426 & 2.5 & 2.7 & 2.3 & 3.2 & 2.9 & 1.08 & $0.86-1.34$ & 0.001 \\
\hline No & 20,674 & 5.8 & 5.1 & 5.1 & 7.2 & 6.9 & 1.37 & $1.30-1.46$ & $<0.001$ \\
\hline \multicolumn{10}{|c|}{ Induction of labour } \\
\hline Yes & 5,648 & 6.4 & 5.4 & 5.4 & 8.4 & 7.7 & 1.41 & $1.26-1.58$ & $<0.001$ \\
\hline No & 16,452 & 5.1 & 4.6 & 4.6 & 6.1 & 6.0 & 1.31 & $1.22-1.40$ & $<0.001$ \\
\hline \multicolumn{10}{|c|}{ Augmentation of labour (oxytocin) } \\
\hline Yes & 4,561 & 7.2 & 5.7 & 6.1 & 8.9 & 8.1 & 1.41 & $1.24-1.61$ & $<0.001$ \\
\hline No & 17,539 & 5.0 & 4.6 & 4.5 & 6.1 & 6.0 & 1.31 & $1.23-1.39$ & $<0.001$ \\
\hline \multicolumn{10}{|c|}{ Epidural analgesia } \\
\hline Yes & 8,096 & 7.0 & 5.4 & 6.0 & 9.0 & 7.8 & 1.44 & $1.30-1.59$ & $<0.001$ \\
\hline No & 14,004 & 4.7 & 4.6 & 4.3 & 5.6 & 5.8 & 1.27 & $1.19-1.36$ & $<0.001$ \\
\hline
\end{tabular}

1n refers to number of cases of atonic postpartum hemorrhage.

${ }^{2} \mathrm{P}$ value based on data for all years between 2000 and 2009.

$\mathrm{RR}$ denotes rate ratio and $95 \% \mathrm{Cl}$ denotes $95 \%$ confidence intervals. 
Table 4 Temporal Trends in atonic postpartum hemorrhage with blood transfusion by maternal, fetal and obstetrical characteristics, British Columbia, 2000-2009

\begin{tabular}{|c|c|c|c|c|c|c|c|c|c|}
\hline \multirow[t]{2}{*}{ Parity } & \multicolumn{2}{|c|}{ All years } & \multicolumn{4}{|c|}{ Rate per 10,000 deliveries } & \multicolumn{2}{|c|}{2009 vs. 2000} & \multirow{2}{*}{$\begin{array}{l}\mathrm{P} \text { for } \\
\text { trend }\end{array}$} \\
\hline & $\overline{n^{1}}$ & $\overline{\text { rate }}$ & 2000 & 2001 & 2008 & 2009 & $\overline{R R}$ & $95 \% \mathrm{Cl}$ & \\
\hline Nulliparous & 534 & 15.3 & 20.1 & 19.9 & 39.5 & 31.3 & 1.56 & $1.04-2.34$ & $<0.001$ \\
\hline Parous & 342 & 28.3 & 16.0 & 14.1 & 18.3 & 20.4 & 1.28 & $0.83-1.98$ & 0.04 \\
\hline \multicolumn{10}{|c|}{ Maternal Age (in years) } \\
\hline$<20$ & 56 & 36.6 & 27.3 & 28.6 & 47.7 & 55.8 & 2.05 & $0.67-6.24$ & 0.07 \\
\hline $20-34$ & 612 & 19.8 & 15.8 & 15.0 & 27.3 & 25.5 & 1.61 & $1.13-2.30$ & $<0.001$ \\
\hline$\geq 35$ & 208 & 23.8 & 23.4 & 20.4 & 28.4 & 21.2 & 0.91 & $0.48-1.70$ & 0.41 \\
\hline \multicolumn{10}{|l|}{ BMI } \\
\hline Underweight & 41 & 23.9 & 10.4 & 26.4 & 25.5 & 18.4 & 1.78 & $0.30-10.62$ & 0.10 \\
\hline Normal & 362 & 20.6 & 16.3 & 19.1 & 30.4 & 20.4 & 1.25 & $0.77-2.03$ & 0.03 \\
\hline Overweight & 115 & 19.8 & 17.3 & 13.6 & 25.0 & 24.1 & 1.39 & $0.62-3.08$ & 0.02 \\
\hline Obese & 58 & 17.8 & 10.1 & 6.5 & 27.3 & 18.6 & 1.85 & $0.48-7.14$ & 0.09 \\
\hline \multicolumn{10}{|l|}{ Plurality } \\
\hline Singleton & 832 & 20.5 & 17.0 & 15.3 & 27.0 & 24.8 & 1.46 & $1.07-1.97$ & $<0.001$ \\
\hline Multiple & 44 & 70.7 & 76.3 & 113.9 & 105.6 & 68.0 & 0.89 & $0.24-3.30$ & 0.84 \\
\hline
\end{tabular}

\section{Birthweight (in grams)}

\begin{tabular}{|c|c|c|c|c|c|c|c|c|c|}
\hline$<2500$ & 59 & 27.8 & 5.1 & 59.2 & 39.4 & 29.9 & 5.92 & $0.73-48.08$ & 0.69 \\
\hline 2500-3999 & 637 & 19.0 & 17.2 & 13.8 & 22.5 & 22.0 & 1.28 & $0.91-1.81$ & 0.002 \\
\hline$\geq 4000$ & 177 & 32.3 & 26.0 & 18.8 & 58.3 & 45.4 & 1.75 & $0.92-3.32$ & $<0.001$ \\
\hline \multicolumn{10}{|l|}{ Gestational age (in weeks) } \\
\hline$<28$ & 7 & 20.1 & 0.0 & 34.5 & 24.0 & 21.8 & - & - & 0.69 \\
\hline $28-36$ & 110 & 33.8 & 25.1 & 36.6 & 45.7 & 46.4 & 1.85 & $0.77-4.45$ & 0.05 \\
\hline $37-41$ & 739 & 20.0 & 17.1 & 15.3 & 27.0 & 23.3 & 1.37 & $0.99-1.89$ & $<0.001$ \\
\hline$\geq 42$ & 17 & 26.6 & 35.2 & 0.0 & 16.5 & 34.0 & 0.96 & $0.16-5.75$ & 0.61 \\
\hline \multicolumn{10}{|l|}{ Vaginal delivery } \\
\hline Spontaneous & 321 & 12.9 & 11.8 & 10.2 & 17.6 & 16.4 & 1.39 & $0.87-2.21$ & 0.004 \\
\hline Instrumental & 244 & 54.7 & 31.2 & 41.4 & 73.3 & 73.6 & 2.36 & $1.29-4.32$ & $<0.001$ \\
\hline \multicolumn{10}{|l|}{ Cesarean delivery } \\
\hline No labour & 110 & 20.7 & 26.9 & 18.1 & 21.5 & 24.7 & 0.92 & $0.41-2.04$ & 0.57 \\
\hline With labour, no induction & 129 & 30.4 & 31.2 & 30.0 & 33.7 & 29.0 & 0.93 & $0.43-2.01$ & 0.59 \\
\hline With induction & 72 & 32.2 & 20.3 & 9.3 & 65.0 & 28.8 & 1.42 & $0.42-4.83$ & 0.01 \\
\hline \multicolumn{10}{|l|}{ Previous cesarean } \\
\hline Yes & 111 & 19.8 & 29.5 & 18.4 & 27.6 & 29.1 & 0.99 & $0.50-1.97$ & 0.60 \\
\hline No & 765 & 21.5 & 16.2 & 16.4 & 28.3 & 24.9 & 1.53 & $1.10-2.13$ & $<0.001$ \\
\hline \multicolumn{10}{|l|}{ Induction of labour } \\
\hline Yes & 236 & 26.9 & 19.9 & 18.9 & 44.3 & 31.3 & 1.57 & $0.86-2.86$ & 0.002 \\
\hline No & 640 & 19.7 & 17.3 & 16.0 & 24.1 & 24.0 & 1.39 & 0.99-1.96 & $<0.001$ \\
\hline \multicolumn{10}{|c|}{ Augmentation of labour (oxytocin) } \\
\hline Yes & 172 & 27.3 & 23.2 & 15.4 & 38.4 & 38.0 & 1.64 & $0.86-3.12$ & $<0.001$ \\
\hline No & 704 & 20.2 & 16.9 & 16.9 & 26.2 & 23.1 & 1.37 & $0.98-1.92$ & $<0.001$ \\
\hline \multicolumn{10}{|l|}{ Epidural analgesia } \\
\hline Yes & 340 & 29.4 & 23.4 & 20.9 & 40.2 & 35.4 & 1.51 & $0.92-2.48$ & $<0.001$ \\
\hline No & 536 & 18.1 & 15.9 & 15.1 & 23.2 & 21.4 & 1.35 & $0.93-1.96$ & 0.003 \\
\hline
\end{tabular}

${ }^{1} \mathrm{n}$ refers to number of cases of atonic postpartum hemorrhage with blood transfusion.

${ }^{2} \mathrm{P}$ value based on data for all years between 2000 and 2009.

$\mathrm{RR}$ denotes rate ratio and $95 \% \mathrm{Cl}$ denotes $95 \%$ confidence intervals. 
represented one of the smaller regions and rates by year fluctuated somewhat even though the linear trend was statistically significant (Table 2). The fact that postpartum hemorrhage with hysterectomy did not increase over the latter half of the study period is a welcome development as Canada [3] (and British Columbia in particular [13]) has higher postpartum hemorrhage with hysterectomy rates as compared with other countries. Increasing use of procedures other than hysterectomy to control bleeding may be responsible for the trend in hysterectomy for postpartum hemorrhage.

Key strengths of our study include use of procedure code definitions for procedures to control bleeding that did not change over time, and postpartum hemorrhage code definitions that remained unchanged between ICD9 and ICD-10. However, as noted, there was a change in the definition of postpartum hemorrhage in 2006. Besides blood transfusions and hysterectomies, other interventions with postpartum hemorrhage have not been reported in previous studies and it is unclear to what extent they have been consistently documented over time. Limitations of our study include use of information from a large perinatal database, which could contain some coding and transcription errors. In addition, multiple comparisons may increase the probability of falsely significant findings. Other limitations include problems with the clinical diagnosis of postpartum hemorrhage since estimation of blood loss during childbirth is difficult to standardize. Our use of different measures of severe postpartum hemorrhage was important for identifying increasing trends in clinically relevant cases of postpartum hemorrhage.

\section{Conclusions}

Atonic postpartum hemorrhage and severe atonic postpartum hemorrhage rates continued to increase in British Columbia across a range of maternal, fetal and obstetric characteristics. The $46 \%$ increase in atonic postpartum hemorrhage with blood transfusion between 2000 and 2009 is substantial. Given that these increases were similar to findings from various countries and jurisdictions employing different definitions and distinct markers of severity, further research is required to identify and address the cause or causes of the increase in atonic postpartum hemorrhage.

\section{Additional file}

Additional file 1: Table S1. International Classification of Diseases (ICD9, ICD-10), the Canadian Classification of Diagnostic, Therapeutic and Surgical Procedures (CCP), and the Canadian Classification of Interventions (CCI) diagnosis/procedure codes used.

\section{Competing interests}

The authors declare that they have no financial or other competing interests.

\section{Authors' contributions}

AM and KSJ were responsible for the intellectual content of the study proposal; they developed and articulated the conceptual framework and study design. AM, KSJ and JH developed the analytic approach. AM wrote the first draft of the manuscript and analyzed the data. JAH, LL RML and KSJ made substantial contributions to the study design and study proposal drafts; they make substantial contributions to the analysis and interpretation of data and revised the article for important intellectual content. All authors have read and approved the final manuscript.

\section{Acknowledgements}

This work is supported by a Canadian Institutes of Health Research Team grant in Severe Maternal Morbidity (MAH - 115445) and carried out under the auspices of Perinatal Services BC. We appreciate the assistance provided by staff at Perinatal Services BC, particularly Cathe Johnson, Terri Pacheco, Brooke Kinniburgh, Linda Lee, and Kenny Der. Jennifer A. Hutcheon is supported by a Scholar Award from the Michael Smith Foundation for Health Research and K.S. Joseph is supported by the Child and Family Research Institute.

\section{Author details}

${ }^{1}$ Department of Obstetrics and Gynaecology, University of British Columbia and the Children's and Women's Health Centre of British Columbia, Room E418B, Shaughnessy Bldg, 4500 Oak Street, Vancouver, BC V6H 3N1, Canada. ${ }^{2}$ School of Population and Public Health, University of British Columbia, Vancouver, BC, Canada. ${ }^{3}$ Perinatal Services BC, Vancouver, BC, Canada.

Received: 23 February 2012 Accepted: 9 October 2012 Published: 11 October 2012

\section{References}

1. Wise A, Clark V: Strategies to manage major obstetric haemorrhage. Curr Opin Anaesthesiol 2008, 21(3):281-287.

2. Roberts WE: Emergent obstetric management of postpartum hemorrhage. Obstet Gynecol Clin North Am 1995, 22(2):283-302.

3. Knight M, Callaghan WM, Berg C, Alexander S, Bouvier-Colle MH, Ford JB, Joseph KS, Lewis G, Liston RM, Roberts $\mathrm{CL}$, et al: Trends in postpartum hemorrhage in high resource countries: a review and recommendations from the International Postpartum Hemorrhage Collaborative Group. BMC Pregnancy Childbirth 2009, 9:55.

4. Health Canada: Canadian Perinatal Health Report, 2003. Ottawa: Minister of Public Works and Government Services of Canada; 2003.

5. Joseph KS, Rouleau J, Kramer MS, Young DC, Liston RM, Baskett TF: Investigation of an increase in postpartum haemorrhage in Canada. BJOG 2007, 114(6):751-759.

6. Callaghan WM, Kuklina EV, Berg CJ: Trends in postpartum hemorrhage: United States, 1994-2006. Am J Obstet Gynecol 2010, 202(4):353. e351-e356.

7. National Service Scotland: Scottish Confidential Audit of Severe Maternal Morbidity: 3rd Annual Report. In. Aberdeen, Scotland; 2005.

8. Rossen J, Økland I, Bjarte Nilsen O, Eggebø TM: Is There an Increase of Postpartum Hemorrhage, and Is Severe Hemorrhage Associated With More Frequent Use of Obstetric Interventions? Obstet Gynecol Surv 2011, 66(1):18-20.

9. Lutomski JE, Byrne BM, Devane D, Greene RA: Increasing trends in atonic postpartum haemorrhage in Ireland: an 11-year population-based cohort study. BJOG 2012, 119(3):306-314.

10. Ford JB, Roberts CL, Simpson JM, Vaughan J, Cameron CA: Increased postpartum hemorrhage rates in Australia. Int J Gynecol Obstet 2007, 98(3):237-243.

11. Kramer MS, Dahhou M, Vallerand D, Liston R, Joseph KS: Risk factors for postpartum hemorrhage: can we explain the recent temporal increase? J Obstet Gynaecol Can 2011, 33(8):810-819.

12. Bateman BT, Berman MF, Riley LE, Leffert LR: The epidemiology of postpartum hemorrhage in a large, nationwide sample of deliveries. Anesth Analg 2010, 110(5):1368-1373.

13. Say L, Souza JP, Pattinson RC: Maternal near miss-towards a standard tool for monitoring quality of maternal health care. Best Pract Res Clin Obstet Gynaecol 2009, 23(3):287-296.

14. Dupont WD, Plummer D: Using Stata v9 to model complex non-linear relationships with restricted cubic splines: North American Stata Users' Group Meeting 2005, Stata Users Group; 2005. 
15. Harrell FE: Regression modeling strategies: with applications to linear models, logistic regression, and survival analysis. New York: Springer; 2001.

16. Liu S, Joseph KS, Bartholomew S, Fahey J, Lee L, Allen AC, Kramer MS, Sauve $\mathrm{R}$, Young DC, Liston RM: Temporal trends and regional variations in severe maternal morbidity in Canada, 2003 to 2007. J Obstet Gynaecol Can 2010, 32(9):847-855.

17. Canadian Coding Standards for ICD-10-CA and CCI for 2006. http://secure.cihi. ca/estore/productSeries.htm?.pc=PCC189.

18. Nova Scotia Atlee Perinatal Database Report for 2000-2009. http://rcp. nshealth.ca.

19. Phaneuf S, Rodriguez Linares B, TambyRaja RL, MacKenzie IZ, Lopez Bernal A: Loss of myometrial oxytocin receptors during oxytocin-induced and oxytocin-augmented labour. J Reprod Fertil 2000, 120(1):91-97.

doi:10.1186/1471-2393-12-108

Cite this article as: Mehrabadi et al:: Trends in postpartum hemorrhage from 2000 to 2009: a population-based study. BMC Pregnancy and Childbirth 2012 12:108.

\section{Submit your next manuscript to BioMed Central and take full advantage of:}

- Convenient online submission

- Thorough peer review

- No space constraints or color figure charges

- Immediate publication on acceptance

- Inclusion in PubMed, CAS, Scopus and Google Scholar

- Research which is freely available for redistribution 